\title{
Analysis of Complications and Recurrences of Aneurysm Coiling with Special Emphasis on the Stent-Assisted Technique
}

\author{
H. Nishido, M. Piotin, B. Bartolini, S. Pistocchi, H. Redjem, and R. Blanc
}

\begin{abstract}
BACKGROUND AND PURPOSE: Stent-assisted coiling has expanded the treatment of intracranial aneurysms. With the use of continuously compiled data, we reviewed the role and drawbacks of stent-assisted coiling.
\end{abstract}

MATERIALS AND METHODS: We compiled data from consecutive patients from 2003-2012 who underwent coiling, with or without stent assistance. Clinical and angiographic results were analyzed retrospectively.

RESULTS: Of 1815 saccular aneurysms in 1505 patients, 323 (17.8\%) were treated with stents ( 299 procedures) and 1492 ( $82.2 \%$ ) without stents (1400 procedures). Procedure-related complications occurred in $9.4 \%$ with stents versus $5.6 \%$ without stents $(P=.016$, relative risk 1.5 ; $95 \%$ $\mathrm{Cl}, 1.1-2.7)$. Ischemic complications were more frequent in the stent group than in the no-stent group $(7.0 \%$ versus $3.5 \% ; P=.005 ;$ relative risk, $1.7 ; 95 \% \mathrm{Cl} 1.2-2.5)$, as were hemorrhagic complications (2.3\% versus $1.9 \%, P=.64)$. Procedure-induced mortality occurred in $2.7 \%$ (8/299) with stents versus $1.1 \%(15 / 1400)$ without stents $(P=.029$; relative risk, $2.0 ; 95 \% \mathrm{Cl}, 1.1-3.5)$. Logistic regression analysis identified wide-neck aneurysms as the most significant independent predictor of complications. A total of $64.1 \%$ (207/323) of aneurysms treated with stents and $70.3 \%$ (1049/1492) treated without stents have been followed, disclosing angiographic recurrence in 15.5\% (32/207) versus 35.5\% (372/1049), respectively $(P<.0001)$. Logistic regression analysis showed that the presence of a stent was the most important factor for the reduction of angiographic recurrence $(P<.0001$; relative risk, $2.3 ; 95 \% \mathrm{Cl}, 1.6-3.3)$.

CONCLUSIONS: The stent-assisted coiling technique is associated with a significant decrease in recurrences but a significant increase in complications. The treatment of wide-neck aneurysms remains hazardous.

T

he stent-assisted coiling technique has broadened the indication

for coil embolization, and numerous reports have depicted the value of stents in the treatment of cerebral aneurysms. ${ }^{1-6}$

We present herein the clinical and angiographic results of a consecutive series of 1815 aneurysms treated over a 9-year period. The aims of this retrospective study were to place the role of stentassisted coiling into perspective and to determine the factors associated with procedural complications.

\section{MATERIALS AND METHODS}

\section{Data Collection}

From a prospectively gathered data base of all patients with intracranial saccular aneurysms (with no prior endovascular treat-

Received March 1, 2013; accepted after revision May 6

From the Department of Interventional Neuroradiology, Foundation Rothschild Hospital, Paris, France.

Please address correspondence to Michel Piotin, MD, PhD, Department of Interventional Neuroradiology, Foundation Rothschild Hospital, 25 rue Manin, 75019 Paris, France; e-mail: mpiotin@free.fr

http://dx.doi.org/10.3174/ajnr.A3658 ment) who were treated with coils in our institution between January 2003 (when we initiated the use of self-expandable stents) and March 2012, 1505 patients were identified and constituted our study population. The data base included data on the patient (age, sex), the endovascular procedure technique (balloon-assisted, stent-assisted, stand-alone coiling), aneurysm status (ruptured or not), procedure-related morbidity and mortality, immediate and follow-up angiographic results, and the rate of (re-)hemorrhage. All data were reviewed and statistically analyzed. Institutional review board acceptance was obtained for this retrospective study, and the need for informed consent was waived.

\section{Endovascular Procedures}

Coiling was performed under general anesthesia and full anticoagulation with heparin in all cases. In all patients with no history of subarachnoid hemorrhage within the previous 4 weeks, $250 \mathrm{mg}$ aspirin was given intravenously. Heparin was discontinued after embolization in most patients. Whenever stent placement was anticipated, patients were given dual antiplatelet therapy before surgery (75-150 mg clopidogrel, $250 \mathrm{mg}$ aspirin daily initiated 15 
Table 1: Baseline demographics and procedures

\begin{tabular}{|c|c|c|c|c|}
\hline & Total & Stent-Assisted & No Stent & $P$ \\
\hline No. of aneurysms & 1815 & 323 & 1492 & - \\
\hline Age, $y$, mean $\pm S D$ & $50.5 \pm 12.9$ & $51.8 \pm 11.5$ & $50.3 \pm 13.1$ & .009 \\
\hline Ruptured aneurysm, $n(\%)$ & $767(42.3)$ & 38 (11.8) & $729(48.9)$ & $<.0001$ \\
\hline Female, $n(\%)$ & $986(65.5)$ & $196(68.8)$ & $790(64.8)$ & .20 \\
\hline \multicolumn{5}{|l|}{ Location, $n(\%)$} \\
\hline ICA & $647(35.6)$ & $134(41.5)$ & $513(34.4)$ & .015 \\
\hline MCA & $489(26.9)$ & $94(29.1)$ & $395(26.5)$ & .34 \\
\hline AcomA & $446(24.6)$ & 49 (15.2) & $397(26.6)$ & $<.0001$ \\
\hline Vertebrobasilar & $160(8.8)$ & $42(13.0)$ & $118(7.9)$ & .003 \\
\hline Pericallosal & $59(3.3)$ & $2(0.6)$ & $57(3.8)$ & .003 \\
\hline PCA & $14(0.8)$ & $2(0.6)$ & $12(0.8)$ & .73 \\
\hline Aneurysm size, $\mathrm{mm}$, mean $\pm \mathrm{SD}$ & $7.1 \pm 4.0$ & $8.2 \pm 4.7$ & $6.8 \pm 3.8$ & $<.0001$ \\
\hline Neck size, $\mathrm{mm}$, mean $\pm \mathrm{SD}$ & $3.8 \pm 1.9$ & $5.0 \pm 2.6$ & $3.6 \pm 1.6$ & $<.0001$ \\
\hline Multiple, $n(\%)$ & $1078(59.4)$ & $147(45.5)$ & $931(62.4)$ & .004 \\
\hline AVM-related, $n(\%)$ & $36(2.0)$ & $2(0.6)$ & $34(2.3)$ & .052 \\
\hline No. of procedures & 1699 & 299 & 1400 & - \\
\hline \multicolumn{5}{|c|}{ No. of aneurysms treated in same EVT, $n(\%)$} \\
\hline 1 & $1591(93.6)$ & $275(92.0)$ & $1316(94.0)$ & \\
\hline 2 & $100(5.9)$ & $24(8.0)$ & $76(5.4)$ & \\
\hline 3 & $8(0.5)$ & 0 & $8(0.6)$ & \\
\hline Balloon-assisted, $n(\%)$ & $1017(56.0)$ & $149(46.1)$ & $868(58.2)$ & $<.0001$ \\
\hline Packing density, $\%$, mean $\pm S D$ & $26.8 \pm 12.3$ & $24.6 \pm 11.1$ & $27.3 \pm 12.5$ & $<.0001$ \\
\hline
\end{tabular}

Note:-AcomA indicates anterior communicating artery; EVT, endovascular treatment; PCA, posterior cerebral artery.

days before the procedure and continued for 6 months). There were no strict exclusion criteria, but a massive subarachnoid hemorrhage potentially requiring ventricular drainage was considered to be a contraindication to stent placement.

\section{Follow-Up Protocol}

Our standard follow-up protocol consisted of fixed angiographic follow-up, the first follow-up being performed at 1-6 months after endovascular treatment (depending of the quality of the initial angiographic occlusion and the presentation). The second angiographic follow-up was performed 12 months after the first follow-up, and the third follow-up was performed 24 months after the second follow-up. In the case of angiographic recurrence and/or associated aneurysms left untreated, the follow-up was continued on a yearly basis. A single reader prospectively evaluated all angiograms. The degree of aneurysm occlusion was classified according to the Montreal simplified classification. ${ }^{7}$ Aneurysm recurrence was dichotomized as absent or present. At follow-up, an aneurysm was considered recurrent if a previously totally occluded aneurysm (class 1 ) had a partial recurrence of the neck (class 2) and/or the sac (class 3). An aneurysm was considered remnant regrowth if a subtotally occluded aneurysm (class 2 or 3) was found to have an increasing neck remnant or residual aneurysm. Aneurysm dimensions were determined on 3D images derived from rotational angiography. Indication for retreatment (class 3 angiographic results) was decided on a case-to-case basis, depending on the patient age and medical history. Aneurysm retreatments were noted.

\section{Statistical Analysis}

Data are presented as means for continuous variables and frequencies for categoric variables. Statistical analysis of categoric variables was carried out by use of $\chi^{2}$ and Wilcoxon tests. Analysis of variance followed by Bonferroni post hoc testing was used to assess differences between the stent-assisted and no-stent groups.
A multivariable logistic regression analysis was carried out to determine predictors of procedural complications and aneurysm recanalization. $P$ values of $\leq .05$ were considered statistically significant. Statistical analysis was carried out with R software version 2.15 (http://www.rproject.org/).

\section{RESULTS \\ Baseline Demographics and Procedures}

Among 1505 consecutive patients, 1815 intracranial aneurysms were treated by coil embolization in 1699 procedures. A total of 323 aneurysms were treated with the assistance of self-expandable stents in 299 procedures; 1492 aneurysms were treated without stent assistance in 1400 procedures. The baseline demographics of all of the aneurysms according to stent use are shown in Table 1.

In the stent-assisted group, $76.2 \%$ (246 aneurysms) had single stent placement and 23.8\% (77 aneurysms) had multiple stent placement (Y, X, or straight overlapping configuration). A balloon-assisted technique was used in $46.1 \%$ in the stent-assisted group (the stent was deployed after coiling), including $6.8 \%(22 / 323)$ of bailed-out stent placement, versus $58.2 \%$ in the no-stent group $(P<.0001)$. In $53.3 \%$ of aneurysms (172/323), the stents were delivered before coiling (145 trans-cell, 16 jailed-catheter, and 11 stent-jack techniques).

\section{Immediate and Follow-Up Angiographic Results}

Immediately, there were more complete obliterations in the nostent group and more residual aneurysms in the stent-assisted group, but this trend was reversed at last follow-up (Table 2).

Angiographic follow-up was available for 1256 of 1815 aneurysms (69.2\%) (Table 3). The no-stent group had a longer mean follow-up $(P=.0004)$. The stent-assisted group had fewer angiographic recurrences $(P<.0001)$. Of the 1492 aneurysms treated with coils, 140 (9.4\%) were retreated, whereas $20(6.2 \%)$ of the 323 stent-assisted coiled aneurysms were retreated $(P=.084)$.

\section{Risk Factors for Angiographic Recurrence}

In the univariate analysis, the risk factors for angiographic recurrence were ruptured status at presentation, larger aneurysm size, no stent, wider neck, younger age, and lower coil packing attenuation (Table 4). The identified reductive factor for angiographic recurrence was multiple aneurysms. In the logistic regression analysis, the independent variables were ruptured status at presentation, absence of stent, larger aneurysm size, lower packing attenuation, younger age, and wider neck (Table 4). In the univariate analysis, the risk factors for aneurysm retreatment were larger aneurysm, lower packing attenuation, and incomplete initial aneurysm occlusion. In the logistic regression analysis, the independent variables favoring retreatment were larger aneurysm size, absence of stent, hemorrhagic presentation, lower packing attenuation, and initial incomplete occlusion (Table 5). 
Table 2: Immediate and follow-up angiographic results

\begin{tabular}{|c|c|c|c|c|}
\hline & Total & $\begin{array}{l}\text { Stent- } \\
\text { Assisted }\end{array}$ & No Stent & $P$ \\
\hline $\begin{array}{c}\text { Immediate result, } \\
n(\%)\end{array}$ & $(n=1815)$ & $(n=323)$ & $(n=1492)$ & - \\
\hline Class $1^{a}$ & 1083 (59.7) & 165 (51.1) & $918(61.5)$ & $<.001$ \\
\hline Class $2^{\mathrm{b}}$ & 307 (16.9) & 44 (13.6) & 263 (17.6) & .08 \\
\hline Class $3^{c}$ & $425(23.4)$ & 114 (35.3) & $311(20.8)$ & $<.0001$ \\
\hline $\begin{array}{l}\text { Last follow-up } \\
\text { result, } n(\%)\end{array}$ & $(n=1254)$ & $(n=207)$ & $(n=1047)$ & - \\
\hline Class $1^{\mathrm{a}}$ & 718 (57.3) & $152(73.4)$ & $566(54.1)$ & $<.0001$ \\
\hline Class $2^{b}$ & 319 (25.4) & 30 (14.5) & $289(27.6)$ & $<.0001$ \\
\hline Class $3^{c}$ & $217(17.4)$ & $25(12.1)$ & $192(18.3)$ & .04 \\
\hline
\end{tabular}

Table 3: Angiographic recurrence

\begin{tabular}{lcccc}
\hline & Total & $\begin{array}{c}\text { Stent- } \\
\text { Assisted }\end{array}$ & No Stent & $\boldsymbol{P}$ \\
\hline $\begin{array}{c}\text { No. of aneurysms } \\
\text { followed }\end{array}$ & 1254 & 207 & 1047 & - \\
$\begin{array}{c}\text { Cumulative follow-up, } \\
\text { mo, median (range) }\end{array}$ & $20.0(1-122)$ & $16.0(1-69)$ & $21.0(1-122)$ & .0004 \\
\begin{tabular}{c} 
Recurrence, $n(\%)$ \\
\hline
\end{tabular} & $404(32.2)$ & $32(15.5)$ & $372(35.5)$ & $<.0001$ \\
\hline
\end{tabular}

Table 4: Risk factors for angiographic recurrence

\begin{tabular}{|c|c|c|c|c|}
\hline & $\begin{array}{c}\text { Univariate } \\
P\end{array}$ & $\begin{array}{l}\text { Relative } \\
\text { Risk }\end{array}$ & $95 \% \mathrm{Cl}$ & $\begin{array}{c}\text { Logistic } \\
\text { Regression } \\
P\end{array}$ \\
\hline $\begin{array}{l}\text { Younger age } \\
\text { Location }\end{array}$ & .004 & & & .008 \\
\hline ICA & .056 & 0.84 & $0.70-1.00$ & \\
\hline MCA & .72 & 1.04 & $0.86-1.25$ & \\
\hline AcomA & .39 & 1.09 & $0.90-1.32$ & \\
\hline Vertebrobasilar & .82 & 1.05 & $0.78-1.37$ & \\
\hline Pericallosal & .054 & 1.50 & $0.99-2.03$ & \\
\hline PCA & .50 & 0.56 & $0.10-1.63$ & \\
\hline Sac size & $<.0001$ & & & $<.00001$ \\
\hline Neck size & .001 & & & .02 \\
\hline Packing density & .013 & & & .005 \\
\hline $\begin{array}{l}\text { Cumulative follow-up } \\
\text { period }\end{array}$ & .33 & & & \\
\hline Balloon-assisted & .82 & 0.98 & $0.83-1.16$ & \\
\hline SAH & $<.0001$ & 1.72 & $1.46-2.02$ & $<.00001$ \\
\hline No stent & $<.0001$ & 2.30 & $1.65-3.28$ & $<.00001$ \\
\hline
\end{tabular}

Note:-AcomA indicates anterior communicating artery; PCA, posterior cerebral artery.

Table 5: Risk factors for retreatment

\begin{tabular}{lcc}
\hline & Univariate $\boldsymbol{P}$ & Logistic Regression $\boldsymbol{P}$ \\
\hline Sac size & $<.001$ & $<.001$ \\
Stent & .084 & .0039 \\
SAH & .098 & .0024 \\
Packing density & $<.001$ & .019 \\
Initial occlusion & $<.001$ & $<.001$ \\
\hline
\end{tabular}

\section{Procedure-Related Complications}

The procedure-related complications were counted for any intracranial hemorrhages (including a wire perforation or an aneurysm rupture) and any ischemic events (that resulted in patient morbidity or mortality). Hydrocephalus after the treatment of unruptured aneurysms was also counted as a complication. In the no-stent group, procedure-related complications occurred in $5.6 \%$ of procedures,
Table 6: Procedure-related complications

\begin{tabular}{lcccc}
\hline & Total & $\begin{array}{c}\text { Stent- } \\
\text { Assisted }\end{array}$ & $\begin{array}{c}\text { No } \\
\text { Stent }\end{array}$ & $\chi^{2}$ \\
\hline No. of procedures & 1699 & 299 & 1400 & - \\
Complications, $n(\%)$ & $107(6.3)$ & $28(9.4)$ & $79(5.6)$ & $0.016^{\mathrm{a}}$ \\
$\quad$ Ischemia & $70(4.1)$ & $21(7.0)$ & $49(3.5)$ & $0.005^{\mathrm{a}}$ \\
$\quad$ Hemorrhage & $34(2.0)$ & $7(2.3)$ & $27(1.9)$ & 0.64 \\
$\quad$ Hydrocephalus & $3(0.2)$ & 0 & $3(0.2)$ & 0.42 \\
Complication-related & $23(1.4)$ & $8(2.7)$ & $15(1.1)$ & $0.029^{\mathrm{a}}$ \\
$\quad$ & & & & \\
$\quad$ deaths, $n(\%)$ & & & &
\end{tabular}

including complication-related deaths in $1.1 \%$ (Table 6). The 49 ischemic complications resulted in 5 deaths, and the 27 perforations resulted in 10 deaths. There were 3 hydrocephali after treatment of unruptured aneurysms with hydrogel-coated coils.

In the stent-assisted group, complications occurred in $9.4 \%$ of procedures and led to 8 deaths $(2.7 \%)$. The 21 ischemic events led to 5 deaths, and the 7 hemorrhagic events led to 3 deaths. Overall, there were significantly more complications in the stent-assisted group than in the no-stent group ( $9.4 \%$ versus $5.6 \%$; $P=.016$ ).

In the univariate analysis, the risk factors for procedure-related complications were wider neck, stent-assisted coiling, MCA location, and larger aneurysm. In logistic regression analysis, the independent variable was a wider neck. Stent-assisted coiling and aneurysm size were related to neck width (Table 7).

\section{(Re-)Bleeding After Coiling}

Only 21 of 1815 aneurysms (1.2\%) bled after endovascular treatment (Table 8 ). The rates of (re-)bleeding were $0.3 \%$ in the stentassisted group and $1.4 \%$ in the no-stent group. In the stent-assisted group, 2 patients bled after treatment of unruptured aneurysms ( 1 from the aneurysm 12 months after the treatment; the second was readmitted 3 weeks after the treatment with a remote intraparenchymal hematoma). No rebleeding was seen from previously ruptured aneurysms. In the no-stent group, 1 unruptured aneurysm bled 12 months after coiling (modified Rankin Scale 4). Nineteen rebleedings occurred after coil embolization of 729 ruptured aneurysms (2.6\%) and led to 13 deaths.

\section{DISCUSSION}

Stent-assisted coiling creates a mechanical scaffold to prevent coil protrusion into the parent vessels. Thus, the indication for this technique had mostly been motivated by aneurysm morphology (large neck). Accordingly, our stent-assisted group included aneurysms with wider necks. Ruptured aneurysms were underrepresented to avoid antiplatelet therapy in the setting of subarachnoid hemorrhage. In the stent-assisted group, internal carotid and MCA aneurysms were overrepresented, whereas posterior circulation and pericallosal aneurysms were scarce, explained by a lower incidence of wide-neck aneurysms in these locations. Multiple aneurysms, which were more often treated with coiling alone, tended to have a smaller size, a narrower neck, and fewer ruptured aneurysms compared with the group of single aneurysms.

\section{Immediate and Follow-Up Angiographic Results}

Immediate angiographic complete occlusions were obtained less frequently in the stent-assisted than in the no-stent group (51.1\% versus $61.5 \%)$. This is because larger aneurysms were more frequent in the 
stent-assisted group and because dual antiplatelet therapy affected the immediate intra-aneurysmal thrombosis. Catheter kickback out of the stent also affected tight packing. Conversely, at follow-up, complete occlusions increased to $73.4 \%$ in the stent-assisted group, whereas these diminished to $54.0 \%$ in the no-stent group. For stentassisted coiling, numerous articles have reported a broad range (13.2-94.4\%) of immediate complete occlusion. ${ }^{1,2,8-13}$ However, similar to the present series, most mid-to-long-term follow-up series have reported augmented rates of angiographic complete occlusion at follow-up (range, 54-81\%). ${ }^{8-14}$

\section{Angiographic Recurrences}

Recurrences were statistically less likely in the stent-assisted group (15.5\% versus $35.5 \%$; $P<.0001$ ). Low rates of recurrence for stent-assisted coiling have also been reported in other recent studies (range, $0-15.2 \%){ }^{8,10,11,13-15}$ In line with our findings, rup-

Table 7: Risk factors for procedure-related complications

\begin{tabular}{|c|c|c|c|c|}
\hline & \multicolumn{3}{|c|}{ Relative } & \multirow{2}{*}{$\begin{array}{c}\text { Logistic } \\
\text { Regression } P\end{array}$} \\
\hline & Univariate $P$ & Risk & $95 \% \mathrm{Cl}$ & \\
\hline Age & .16 & & & \\
\hline \multicolumn{5}{|l|}{ Location } \\
\hline MCA & .01 & 1.67 & $1.15-2.43$ & .058 \\
\hline Vertebrobasilar & .08 & 0.40 & $0.15-1.07$ & - \\
\hline ICA & .84 & 0.94 & $0.64-1.38$ & - \\
\hline AcomA & .48 & 0.83 & $0.53-1.30$ & - \\
\hline Pericallosal & 1.00 & 0.85 & $0.28-2.50$ & - \\
\hline PCA & .71 & NA & & - \\
\hline $\begin{array}{l}\text { No. of aneurysms in same EVT } \\
\text { (multiple vs single) }\end{array}$ & .98 & 1.04 & $0.58-1.79$ & - \\
\hline Size & .04 & & & .94 \\
\hline Neck & $<.001$ & & & $.02^{\mathrm{a}}$ \\
\hline Balloon-assisted & 1.00 & 1.02 & $0.70-1.47$ & - \\
\hline SAH & .98 & 1.01 & $0.70-1.47$ & - \\
\hline Stent & .016 & 1.66 & $1.07-2.55$ & 0.15 \\
\hline Single (vs Y) stenting & .36 & 1.59 & $0.73-3.47$ & - \\
\hline
\end{tabular}

tured aneurysms, larger size, lower packing attenuation, and wide necks are well-established risk factors for recurrence. ${ }^{7,16-20} \mathrm{We}$ also identified younger age to be a risk factor for recurrence. The effect of age is not yet clear, but younger age was one of the predicting factors of late retreatment in the International Subarachnoid Aneurysm Trial. ${ }^{21}$

Multiple aneurysms reduced the likelihood of recurrence, but these aneurysms were generally smaller, had narrower necks, and had fewer ruptured lesions.

In our study, the use of a balloon-assisted technique had no influence on recurrence. Conversely, Shapiro et $\mathrm{al}^{22}$ found both initial and follow-up aneurysm occlusion rates to be higher in balloon-assisted cases. In our study, an absence of a stent was identified as one of the most relevant factors for recurrence. Our results help to confirm the evidence that stent-assisted coiling augments treatment durability and contributes to progressive occlusion. ${ }^{10,23,24}$ This durability can be explained by the combination of biologic, geometric, and hemodynamic mechanisms. ${ }^{25-27}$

\section{Procedural Complications}

Our no-stent results show occurrences of complications $(5.6 \%)$ and mortality (1.1\%) similar to various other series without stents. ${ }^{28-31}$ Henkes et $\mathrm{al}^{28}$ reported procedural morbidity of $5.0 \%$ and mortality of $1.5 \%$. van Rooij et $\mathrm{al}^{30}$ reported procedural complications with a morbidity rate of $3.2 \%$ and a mortality rate of $2.6 \%$. A recent meta-analysis for unruptured aneurysms (mainly of studies without the use of stents) found a morbidity rate of $4.8 \%$ and a mortality rate of $1.2 \% .^{29}$ Our complication and mortality

Table 8: Aneurysm (re)-bleeding summary

\begin{tabular}{|c|c|c|c|c|c|c|}
\hline Case/Sex/Age & Presentation & Use of Antiplatelet & $\begin{array}{c}\text { Initial Aneurysm } \\
\text { Occlusion }\end{array}$ & Stent & $\begin{array}{c}\text { (Re)-Bleeding } \\
\text { Delay }\end{array}$ & $\begin{array}{c}\text { Outcome } \\
\text { (mRS) }\end{array}$ \\
\hline $1 / F / 71$ & $\mathrm{SAH}$ & None & 1 & None & Day 1 & 6 \\
\hline $2 / F / 68$ & Fortuitous & None & 1 & None & $12 \mathrm{mo}$ & 4 \\
\hline $3 / M / 46$ & $\mathrm{SAH}$ & None & 3 & None & Day 10 & 6 \\
\hline $4 / F / 48$ & $\mathrm{SAH}$ & None & 3 & None & Day 10 & 6 \\
\hline $5 / F / 65$ & $\mathrm{SAH}$ & $8 \mathrm{mg}$ i.a. of abciximab during procedure & 1 & None & Hour 14 & 6 \\
\hline $6 / F / 57$ & $\mathrm{SAH}$ & None & 1 & None & Day 1 & 4 \\
\hline $7 / M / 35$ & $\mathrm{SAH}$ & None & 1 & None & Hour 6 & 6 \\
\hline $8 / M / 48$ & $\mathrm{SAH}$ & None & 3 & None & Hour 8 & 6 \\
\hline $9 / F / 55$ & SAH & None & 3 & None & $89 \mathrm{mo}$ & 6 \\
\hline $10 / F / 37$ & $\mathrm{SAH}$ & None & 2 & None & $57 \mathrm{mo}$ & 6 \\
\hline $11 / F / 52$ & $\mathrm{SAH}$ & None & 1 & None & 17 mo & 1 \\
\hline $12 / F / 81$ & $\mathrm{SAH}$ & None & 3 & None & Day 4 & 6 \\
\hline $13 / F / 55$ & SAH & None & 3 & None & $4 \mathrm{mo}$ & 6 \\
\hline $14 / M / 52$ & Fortuitous & Clopidogrel + aspirin & 2 & Yes & $12 \mathrm{mo}$ & 1 \\
\hline $15 / M / 41$ & $\mathrm{SAH}$ & None & 1 & None & Day 18 & 6 \\
\hline $16 / M / 52$ & $\mathrm{SAH}$ & $4 \mathrm{mg}$ i.a. of abciximab during procedure & 1 & None & Day 1 & 6 \\
\hline $17 / F / 51$ & $\mathrm{SAH}$ & $4 \mathrm{mg}$ i.a. of abciximab during procedure & 1 & None & Hour 4 & 6 \\
\hline $18 / M / 20$ & $\mathrm{SAH}$ & No & 1 & None & Day 22 & 1 \\
\hline 19/M/69 & Fortuitous & Clopidogrel + aspirin & 1 & Yes & Day 21 & 6 \\
\hline $20 / F / 56$ & $\mathrm{SAH}$ & No & 3 & None & Day 1 & 6 \\
\hline $21 / F / 56$ & SAH & No & 3 & None & $2 \mathrm{mo}$ & 1 \\
\hline
\end{tabular}

Note:-i.a. indicates intra-arterial. 
rates in the stent-assisted group were $9.4 \%$ and $2.7 \%$, respectively. These are similar to other series of stent-assisted coiling that have reported $2.9-11 \%$ morbidity rate and $0-4.8 \%$ mortality rate. ${ }^{1,3,5,8,32,33}$ Overall, our complication rate in the stent-assisted group was higher than in the stand-alone coiling series $(9.4 \%$ versus $5.6 \% ; P=.016)$. The use of a stent was linked to a significantly higher morbidity in our series, but not as an independent factor because stents were generally used in aneurysms with wider necks.

Three cases $(0.2 \%)$ of hydrocephalus occurred after the treatment of unruptured aneurysms with hydrogel-coated coils, and there were no cases in the smaller stent-assisted group. The HELPS trial also reported that there was no significant difference in the occurrence of hydrocephalus between the hydrogel-coated and bare-platinum coil groups. ${ }^{34}$

A large aneurysm size was identified as a risk factor for complications but was not identified as an independent value, unlike neck width, which also appeared to be an independent factor. In the CLARITY study, aneurysms $>10 \mathrm{~mm}$ had a higher risk of thromboembolic events, with higher morbidity-mortality rates compared with smaller lesions. ${ }^{35}$ Similar results have also been reported in the ATENA study. ${ }^{33}$ Moreover, the amount of procedural aneurysmal ruptures was significantly higher for smaller aneurysms. ${ }^{33,36}$ In CLARITY, the morbidity-mortality secondary to thromboembolic events was higher in the group of aneurysms for which the neck was $>4 \mathrm{~mm} .{ }^{35}$ In the same study, a neck $>4$ $\mathrm{mm}$ was also identified as an independent risk factor of intraoperative rupture. ${ }^{35}$

As in our study, age was not identified as a risk factor for complications in the series from van Rooij et al. ${ }^{30}$ However, Sedat et $\mathrm{al}^{14}$ reported that thromboembolic events were more frequent among elderly patients, whereas in the CLARITY study, procedural ruptures were more likely to occur in patients $<65$ years of age. ${ }^{35}$ As did van Rooij et al, ${ }^{30}$ we did not find any specific locations to be linked with complications. However, we found that MCA location was a risk factor in the univariate analysis. Similarly, the CLARITY study reported that thromboembolic events were more likely to occur in MCA aneurysms than in aneurysms in other locations, such as intraoperative ruptures. ${ }^{35}$ The treatment of several aneurysms during the same procedure was not found to result in more complications, as was previously found in the CLARITY study. ${ }^{35}$ However, only $6.4 \%$ of our procedures were multiple aneurysm treatments. The balloon-assisted technique was not identified as a risk factor for complications, unlike in some previous reports. ${ }^{28,30,37}$ However, the ATENA and CLARITY studies showed that the balloon-assisted technique was as safe as conventional coiling. ${ }^{33,35}$ A ruptured aneurysm was not found to be a significant risk factor for complications in the current study. However, this is contrary to various other studies. For example, $\mathrm{Ng}$ et $\mathrm{al}^{18}$ reported that intraprocedural ruptures occurred more frequently for ruptured aneurysms than for unruptured aneurysms. Ishibashi et $\mathrm{al}^{38}$ reported that hyper intensities were seen more frequently on diffusion-weighted MRI after the treatment of ruptured than unruptured aneurysms. Also, Ross and Dhillon ${ }^{39}$ reported that the risks of vessel or aneurysm rupture or thromboembolic stroke were greater during the treatment of ruptured aneurysms. Similarly, Park et $\mathrm{al}^{36}$ reported that pro- cedural morbidity and mortality rates were higher for ruptured than unruptured aneurysms. We cannot postulate as to why our results are different from these studies.

\section{(Re-)Bleeding}

The (re-)bleeding rates were low for both stented and nonstented aneurysms, which is in line with previous reports. ${ }^{40-43}$ None of the ruptured aneurysms that were treated with stent-assisted coiling rebled. However, no definitive conclusions can be drawn because of the small number of ruptured aneurysms that were treated with stents.

\section{Study Limitations}

Our study has the inherent limitations of a retrospective study. The duration of follow-up was shorter for stented aneurysms because most of the stents were implanted during the last 6 years. Moreover, the rate of aneurysms followed by angiography was lower.

\section{CONCLUSIONS}

The stent-assisted coiling technique was associated with a significant decrease in recurrences but a significant increase in complications. The treatment of wide-neck aneurysms remains more hazardous.

\section{ACKNOWLEDGMENTS}

We thank Thomas Spaety, Arthur Castagnac, and Laurence Salomon from the Department of Clinical Research (data statistical analysis) and Jenny Lloyd (English editing).

Disclosures: Michel Piotin—UNRELATED: Consultancy: Stryker,* Covidien*; Payment for Development of Educational Presentations: Stryker,* Covidien, ${ }^{*} \mathrm{Mi}$ croVention*; Travel/Accommodations/Meeting Expenses Unrelated to Activities Listed: NFocus. * Bruno Bartolini-UNRELATED: Consultancy: Covidien,* Stryker.* Silvia Pistocchi-UNRELATED: Consultancy: Covidien, ${ }^{*}$ Stryker.* Raphaël BlancUNRELATED: Consultancy: Stryker, ${ }^{*}$ Covidien* ( ${ }^{\star}$ money paid to institution).

\section{REFERENCES}

1. Akpek S, Arat A, Morsi H, et al. Self-expandable stent-assisted coiling of wide-necked intracranial aneurysms: a single-center experience. AJNR Am J Neuroradiol 2005;26:1223-31

2. Alfke K, Straube T, Dorner L, et al. Treatment of intracranial broadneck aneurysms with a new self-expanding stent and coil embolization. AJNR Am J Neuroradiol 2004;25:584-91

3. Fiorella D, Albuquerque FC, Deshmukh VR, et al. Usefulness of the Neuroform stent for the treatment of cerebral aneurysms: results at initial (3-6-mo) follow-up. Neurosurgery 2005;56:1191-202

4. Howington JU, Hanel RA, Harrigan MR, et al. The Neuroform stent, the first microcatheter-delivered stent for use in the intracranial circulation. Neurosurgery 2004;54:2-5

5. Lylyk P, Ferrario A, Pasbon B, et al. Buenos Aires experience with the Neuroform self-expanding stent for the treatment of intracranial aneurysms. J Neurosurg 2005;102:235-41

6. Wells-Roth D, Biondi A, Janardhan V, et al. Endovascular procedures for treating wide-necked aneurysms. Neurosurg Focus 2005; 18:E7

7. Raymond J, Guilbert F, Weill A, et al. Long-term angiographic recurrences after selective endovascular treatment of aneurysms with detachable coils. Stroke 2003;34:1398-403

8. Biondi A, Janardhan V, Katz JM, et al. Neuroform stent-assisted coil embolization of wide-neck intracranial aneurysms: strategies in stent deployment and midterm follow-up. Neurosurgery 2007;61: 460-69 
9. Fargen KM, Hoh BL, Welch BG, et al. Long-term results of Enterprise stent-assisted coiling of cerebral aneurysms. Neurosurgery 2012;71:239-44

10. Lubicz B, Bandeira A, Bruneau M, et al. Stenting is improving and stabilizing anatomical results of coiled intracranial aneurysms. Neuroradiology 2009;51:419-25

11. Maldonado IL, Machi P, Costalat V, et al. Neuroform stent-assisted coiling of unruptured intracranial aneurysms: short- and midterm results from a single-center experience with 68 patients. AJNR Am J Neuroradiol 2011;32:131-36

12. Mocco J, Fargen KM, Albuquerque FC, et al. Delayed thrombosis or stenosis following Enterprise-assisted stent-coiling: is it safe? Midterm results of the Interstate Collaboration of Enterprise Stent Coiling. Neurosurgery 2011;69:908-14

13. Yahia AM, Latorre JG, Gordon V, et al. Progressive occlusion of aneurysms in Neuroform stent-assisted treatment of intracranial aneurysms. J Neurol Neurosurg Psychiatry 2011;82:278-82

14. Sedat J, Chau Y, Mondot L, et al. Endovascular occlusion of intracranial wide-necked aneurysms with stenting (Neuroform) and coiling: mid-term and long-term results. Neuroradiology 2009;51: 401-09

15. Fiorella D, Albuquerque FC, Woo H, et al. Neuroform stent assisted aneurysm treatment: evolving treatment strategies, complications and results of long term follow-up. J Neurointerv Surg 2010;2:16-22

16. Hope JK, Byrne JV, Molyneux AJ. Factors influencing successful angiographic occlusion of aneurysms treated by coil embolization. AJNR Am J Neuroradiol 1999;20:391-99

17. Murayama Y, Nien YL, Duckwiler G, et al. Guglielmi detachable coil embolization of cerebral aneurysms: 11 years' experience. J Neurosurg 2003;98:959-66

18. Ng P, Khangure MS, Phatouros CC, et al. Endovascular treatment of intracranial aneurysms with Guglielmi detachable coils: analysis of midterm angiographic and clinical outcomes. Stroke 2002;33: $210-17$

19. Nguyen TN, Hoh BL, Amin-Hanjani S, et al. Comparison of ruptured vs unruptured aneurysms in recanalization after coil embolization. Surg Neurol 2007;68:19-23

20. Tamatani S, Ito $\mathrm{Y}, \mathrm{Abe} \mathrm{H}$, et al. Evaluation of the stability of aneurysms after embolization using detachable coils: correlation between stability of aneurysms and embolized volume of aneurysms. AJNR Am J Neuroradiol 2002;23:762-67

21. Campi A, Ramzi N, Molyneux AJ, et al. Retreatment of ruptured cerebral aneurysms in patients randomized by coiling or clipping in the International Subarachnoid Aneurysm Trial (ISAT). Stroke 2007;38:1538-44

22. Shapiro M, Babb J, Becske $T$, et al. Safety and efficacy of adjunctive balloon remodeling during endovascular treatment of intracranial aneurysms: a literature review. AJNR Am J Neuroradiol 2008; 29:1777-81

23. Lawson MF, Newman WC, Chi YY, et al. Stent-associated flow remodeling causes further occlusion of incompletely coiled aneurysms. Neurosurgery 2011;69:598-604

24. Piotin M, Blanc R, Spelle L, et al. Stent-assisted coiling of intracranial aneurysms: clinical and angiographic results in 216 consecutive aneurysms. Stroke 2010;41:110-15

25. Hirabayashi M, Ohta M, Rufenacht DA, et al. Characterization of flow reduction properties in an aneurysm due to a stent. Phys Rev $E$ Stat Nonlin Soft Matter Phys 2003;68:021918

26. Huang QH, Wu YF, Xu Y, et al. Vascular geometry change because of endovascular stent placement for anterior communicating artery aneurysms. AJNR Am J Neuroradiol 2011;32:1721-25
27. Lopes D, Sani S. Histological postmortem study of an internal carotid artery aneurysm treated with the Neuroform stent. Neurosurgery 2005;56:E416

28. Henkes H, Fischer S, Weber W, et al. Endovascular coil occlusion of 1811 intracranial aneurysms: early angiographic and clinical results. Neurosurgery 2004;54:268-85

29. Naggara ON, White PM, Guilbert F, et al. Endovascular treatment of intracranial unruptured aneurysms: systematic review and metaanalysis of the literature on safety and efficacy. Radiology 2010;256: $887-97$

30. van Rooij WJ, Sluzewski M, Beute GN, et al. Procedural complications of coiling of ruptured intracranial aneurysms: incidence and risk factors in a consecutive series of 681 patients. AJNR Am J Neuroradiol 2006;27:1498-501

31. Wiebers DO, Whisnant JP, Huston J 3rd, et al. Unruptured intracranial aneurysms: natural history, clinical outcome, and risks of surgical and endovascular treatment. Lancet 2003;362:103-10

32. Fiorella D, Albuquerque FC, Han P, et al. Preliminary experience using the Neuroform stent for the treatment of cerebral aneurysms. Neurosurgery 2004;54:6-17

33. Pierot L, Spelle L, Vitry F, ATENA Investigators. Immediate clinical outcome of patients harboring unruptured intracranial aneurysms treated by endovascular approach: results of the ATENA study. Stroke 2008;39:2497-504

34. White PM, Lewis SC, Nahser H, et al. Hydrocoil endovascular aneurysm occlusion and packing study (HELPS trial): procedural safety and operator-assessed efficacy results. AJNR Am J Neuroradiol 2008;29:217-23

35. Pierot L, Cognard C, Anxionnat R, et al, CLARITY Investigators. Ruptured intracranial aneurysms: factors affecting the rate and outcome of endovascular treatment complications in a series of 782 patients (CLARITY study). Radiology 2010;256:916-23

36. Park HK, Horowitz M, Jungreis C, et al. Periprocedural morbidity and mortality associated with endovascular treatment of intracranial aneurysms. AJNR Am J Neuroradiol 2005;26:506-14

37. Sluzewski M, van Rooij WJ, Beute GN, et al. Balloon-assisted coil embolization of intracranial aneurysms: incidence, complications, and angiography results. J Neurosurg 2006;105:396-99

38. Ishibashi T, Murayama $Y$, Saguchi $T$, et al. Thromboembolic events during endovascular coil embolization of cerebral aneurysms. Interv Neuroradiol 2006;12:112-16

39. Ross IB, Dhillon GS. Complications of endovascular treatment of cerebral aneurysms. Surg Neurol 2005;64:12-19

40. Cho YD, Lee JY, Seo JH, et al. Early recurrent hemorrhage after coil embolization in ruptured intracranial aneurysms. Neuroradiology 2012;54:719-26

41. Ferns SP, Majoie CB, Sluzewski M, et al. Late adverse events in coiled ruptured aneurysms with incomplete occlusion at 6-month angiographic follow-up. AJNR Am J Neuroradiol 2010;31:464-69

42. Lanterna LA, Tredici G, Dimitrov BD, et al. Treatment of unruptured cerebral aneurysms by embolization with Guglielmi detachable coils: case-fatality, morbidity, and effectiveness in preventing bleeding: a systematic review of the literature. Neurosurgery 2004;55:767-78

43. Molyneux AJ, Kerr RS, Birks J, et al. Risk of recurrent subarachnoid haemorrhage, death, or dependence and standardised mortality ratios after clipping or coiling of an intracranial aneurysm in the International Subarachnoid Aneurysm Trial (ISAT): long-term follow-up. Lancet Neurol 2009;8:427-43 